\title{
Spatial data processing for the purpose of video games*
}

\begin{abstract}
Advanced terrain models are currently commonly used in many video/computers games. Professional GIS technologies, existing spatial datasets and cartographic methodology are more widely used in their development. This allows for achieving a realistic model of the world. On the other hand, the so-called game engines have very high capability of spatial data visualization. Preparing terrain models for the purpose of video games requires knowledge and experience of GIS specialists and cartographers, although it is also accessible for non-professionals. The authors point out commonness and variety of use of terrain models in video games and the existence of a series of ready, advanced tools and procedures of terrain model creating. Finally the authors describe the experiment of performing the process of data modeling for "Condor Soar Simulator".
\end{abstract}

Keywords: digital cartography, computer simulators, video games, computer games, virtual world, spatial data modeling, GIS

\section{Introduction}

As written in the article by D. Gotlib and D. Chądzyńska (2015), a map frequently constitutes a significant element of many games, and especially of video games. Currently, in literature and social circuit there function many definitions of the term "map". However, there is no doubt that a contemporary definition of a map is not limited to $2 \mathrm{D}$ cartographic images. Many contemporary cartographic elaborations are prepared in 3D. Contemporary video games require that $2 \mathrm{D}$ and $3 \mathrm{D}$ terrain models used in many of them have to be no less precise and detailed than those used for professional geoinformational systems. Often the requirements are even more strict. There is not only a need for creation of fictional worlds, but also for placing the player in a virtual reality resembling the real world as much as possible. Therefore it is

* The substantial parts of the diploma thesis carried out by Dominika Chądzyńska in 2015 within the Department of Cartography at the Faculty of Geodesy and Cartography, Warsaw University of Technology, are used in the article (supervisor D. Gotlib). unavoidable that various available spatial databases are used and processed with professional technologies. This necessitates a flow of knowledge between game developers and cartographers. The task for cartographers could be to prepare more and more complex data models for game developers, who in turn can, and should use the theory and practice of cartography and geo-information to enhance the functionality of developed products. On the other hand, the use of game technology in contemporary geoinformational products can allow for an even better presentation and analysis of space in such applications as spatial planning, navigation, decision-making training, social geoparticiation. Selected issues connected with professional spatial data modeling for the purpose of video games are discussed below.

\section{Methods of using spatial datasets in video games}

The following main ways of using spatial datasets in video games are most common:

1) preparation of spatial data by developers according to their own internal procedures, 
without an option of addition or modification by players (or other people);

2) preparation of spatial data by developers according to their own internal procedures, with an option of addition and modification by players (or other people) using functions integrated in the game;

3) using existing geoinformational components created by subjects independent of game developers, usually without an option of addition or modification by players (or other people);

4) preparation by game developers of external data preparation procedures using independent technologies of other companies, allowing for self-preparation of data by players (or other people) outside of the game environment;

5) preparation by game developers of external data preparation procedures using their own closed technological solutions, allowing for self-preparation of data by players (or other people) outside of the game environment;

The authors discuss the last three of the above possibilities. In the first case we are mostly dealing with games which are developed as add-ons to spatial information systems, spatial data services, geoportals, navigation applications, etc. Currently the most commonly used are perhaps the solutions by Google, e.g. Google Earth, Google Maps and Google Street View. In the second case geoinformational technologies are widely used, especially GIS software. Data preparation uses accessible bases, integrating, generalizing and converting them. In the third case game developers give access to their own SDK ${ }^{1}$ environment for the purpose of creation of a reality model most commonly referred to as "scenery".

\section{Using existing geoinformational components in games}

Google maps and Google Earth are commonly known services which provide spatial information in the form of maps. They can be used for trip planning or to find a specific place on Earth. Not all users are aware, however, that they can also be used for gaming. Google Earth has an integrated flight simulator with a choice of airplane, helicopter, glider, para-

\footnotetext{
${ }^{1}$ SDK (software development kit) - a toolkit for programmers.
}

glider and balloon options. Ship Simulator [1] ${ }^{2}$ developed by Dinther Product Design from New Zealand is a similar product. It uses Google Earth resources and technology to offer a simulation of a cargo ship, passenger ship, barge and a catamaran. A zeppelin flight is also possible. Gaiagi Driver [2] is a car simulator which besides Google Earth and Google Maps (with traffic information) also uses Google Street View and Microsoft Birds View. Monster Milk Truck [3] is an interesting delivery truck simulator using the Earth model from Google Earth.

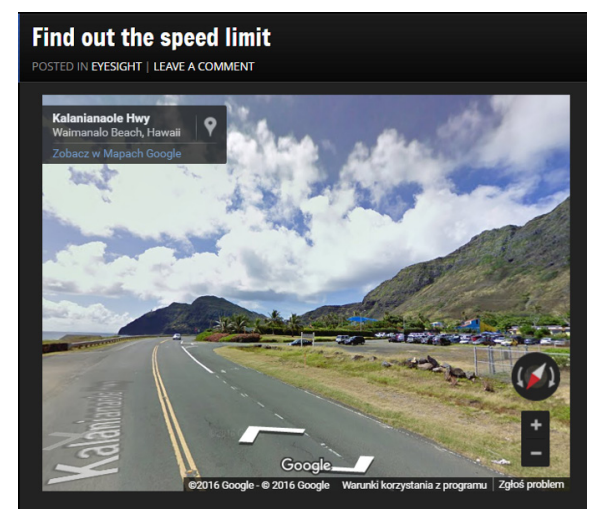

Fig. 1. Example question from Street View Quiz „What is the speed limit here? You must look around"

Simulators are however not the only type of games using Google maps. Street View Quiz [4] (fig. 1) is a good example, in which the user answers questions regarding objects visible in pictures (e.g. speed limit in a shown section of a road). In this case Street View is used. The main task of Geoguessr [5] is marking the place on a map where a particular picture was taken.

MapsTD (fig. 2) is another interesting example. It is a strategic game using the Google Maps engine. The objective of the game is to place various types of armed "towers" (blue and red markers with firing range) along a determined route on the map, so that the enemy (red) markers would not be able to pass between two given points because of the danger of being fired at from the towers.

\footnotetext{
${ }^{2}$ Numbers in [square parentheses] relate to the list of internet sources at the end of the article.
} 


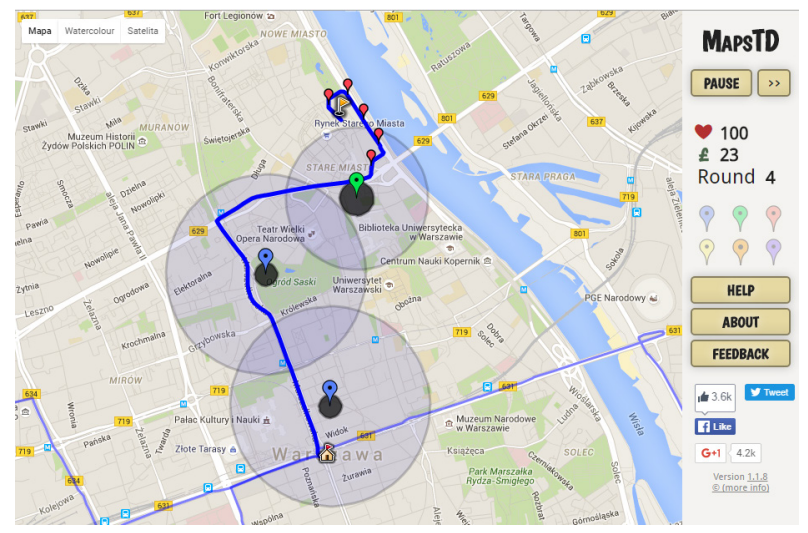

Fig. 2. MapsTD game screen

\section{Data preparation in an external, open GIS environment}

STISIM [6] (fig. 3) car driving simulator is an example of a game, in which spatial data can be individually prepared by users familiar with GIS technologies. "Sceneries" visible in the game are prepared in the ArcGIS environment (fig. 4). They are based on the classic GIS data model. Such an approach significantly facilitates development and updating of scenery and analysis of travelled routes.

GIS data and technology is used not only by developers of simulator games, but also by developers of training games. Training games are used, among others, in crisis management. A good example of such a game is the result of cooperation of a group of scientists from Rochester Institute of Technology with United Nations University Institute for Environment and Human Security in Bonn (Germany). Together

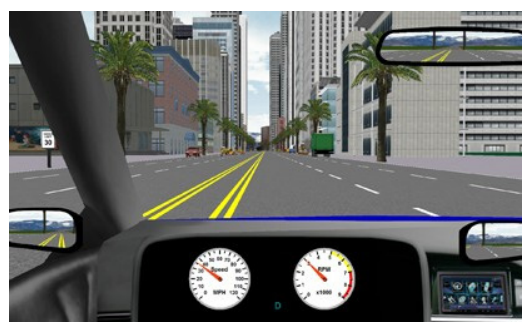

Fig. 3. STISIM car driving simulator screen (source: J.-H. Haunert, C. Brenner, H. Neidhart 2005) they developed a game of the serious game type which works in ArcGIS software environment (K. Blochel et al. 2012). The game makes it possible to evaluate and practice the skills of spatial thinking in people responsible for crisis management in case of natural disaster. In the game there is a scenario in which toxic substances are released on the Rhine bank after a flood. The user is asked a number of questions. Depending on the answers ArcGIS software presents different results of spatial analyses and different presentation of the disaster effect. In the case of using real geospatial data the game can become a useful training tool for real crisis management.

\section{Data preparation in an external environment designed for editing of terrain models}

Some game developers prepare special software which enables users to create and update spatial models. Microsoft Flight Simulator [9] can serve as an example. Terrain models from practically any area of Earth are used in the game (fig. 5) The producer provides a commercial visualization and simulation platform - Microsoft ESP. It includes a number of programming tools (e.g. Terrain SDK) which enable elaboration and edition of own terrain models. There also exists an unofficial plug-in ${ }^{3}$ develop-

\footnotetext{
${ }^{3}$ Plug-in - a programming component (module) extending capabilities of the basic program.
} 


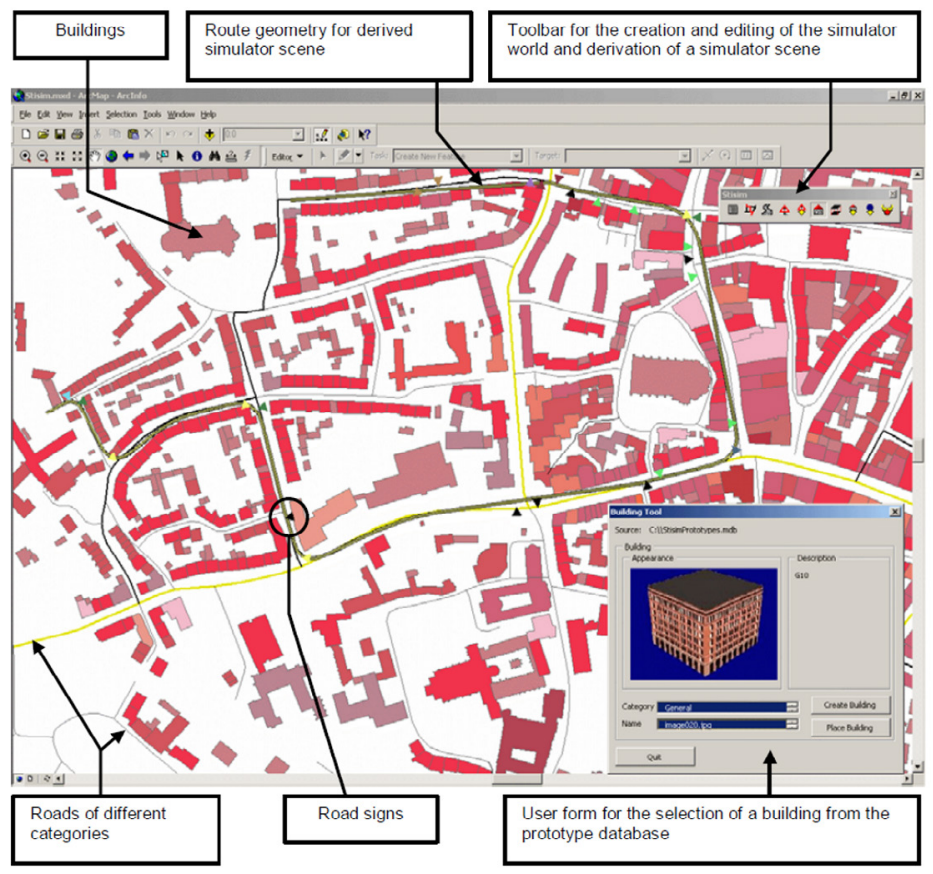

Fig. 4. ArcGIS screen during preparation of spatial data for the STISIM simulator (source: J.-H. Haunert, C. Brenner, H. Neidhart 2005)

ed by third parties which makes it possible to use Google Maps data in this game.

Geospatial data are also often used in games simulating various sports. SSX [8] - a simulator of extreme snowboard rides (fig. 6), which uses real NASA data, is a good example. Altitude models available in the simulator represent important mountain ridges in the world. Games of this type, by using real models of various regions of the world can provide not only entertainment but also some educational value.

Flight Gear [10] (fig. 7) is another example of a game where users have a possibility of creating their own models of space. It is a flight simulator developed under license from GNU GPL ${ }^{4}$, used for academic research, education and entertainment. Additional data concerning terrain are published as so-called World Scenery collections available for download at the

\footnotetext{
${ }^{4}$ GPL (General Public License) - free and open software license.
}

official www site of game developers. Users can also add their own models or terrain data.

"Condor Soaring Simulator" is a good example showing possibilities of using existing geospatial databases for computer games. The authors provided a possibility of creating realistic terrain models (sceneries) for the purpose

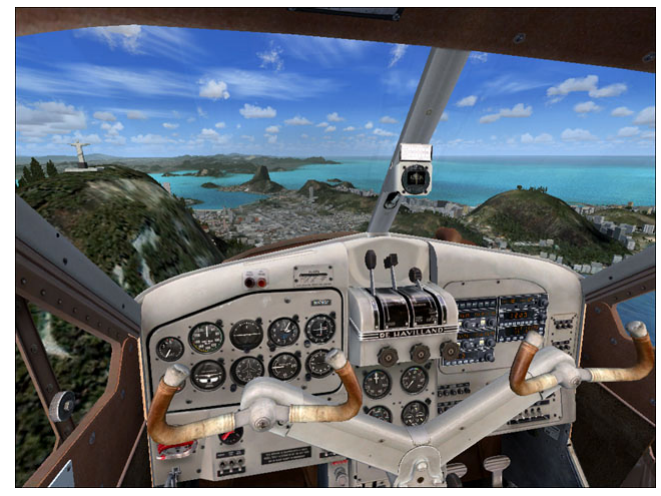

Fig. 5. Visualization of the Rio de Janeiro area in Microsoft Flight Simulator X (source: [9]) 


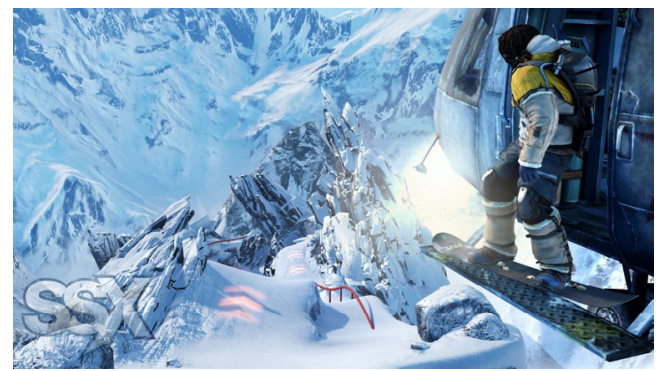

Fig. 6. Visualization from SSX game by EA Games (source: [8])

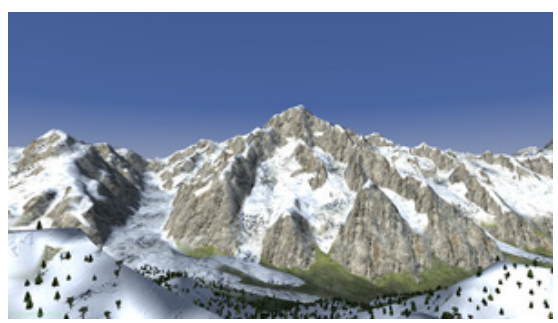

Fig. 7. Visualization of Mont Blanc in the Flight Gear simulator (source: [10])

of the program and made them available to users through e.g. Condor Club website. Further in the article this game will be used as an example for presenting a fairly typical process of preparation of a terrain model for the purpose of a computer simulator game. "Bezmiechowa" glider airfield in south-east Poland was selected for the test.

\section{Possibilities of spatial data modeling for the purpose of games on the example of a glider simulator}

"Condor", the most popular flight simulator among glider pilots, was selected during research for further analysis. It is a good example showing the necessity and capabilities of using geoinformation technologies for developing a model of the World in computer games. Creation of an image of reality for the purpose of the "Condor" simulator consists in creating a so-called scenery. In the context of video games a scenery is a set of information technology components allowing for space projection in a predetermined way. Developers of this game, as well as many other games, provided users with tools (Scenery Toolkit) allowing users to create own sceneries. As a result, many models of the real world are made available online free of charge by their users [12]. Commercial sceneries are also available. From the technical point of view three components of scenery can be distinguished in the games of this type (fig. 8):

1) digital terrain model (DTM) - representing terrain relief,

2) textures - so-called synthetic textures (representing e.g. grass, sand, specific soil type) or realistic texture (orthophotomaps or satellite images), which are superimposed over the terrain model,

3) models of objects - representation of selected terrain objects (buildings, trees, etc.) using 3D graphic techniques (with textures).

Authors of the "Condor" simulator adapted a concept of so-called limited space, with maximum dimensions of $400 \mathrm{~km} \times 400 \mathrm{~km}$ (however due to software efficiency they recommend using sceneries of smaller sizes). The program is optimized for using $\mathrm{SRTM}^{5}$ data as a digital terrain model, synthetic structures (realistic structures can be used as well) and all kinds of 3D overground objects (trees, towns, airports, etc.).

Creating scenery (terrain model) in "Condor" is a complex process consisting of four key subprocesses: preparing source data, creating a terrain model, creating terrain textures and placing 3D objects in the scenery. The scheme of the process of scenery development performed during the described research is presented in fig. 9.

Scenery elaboration usually requires application of many programs and tools - both provided by program authors and coming from different producers. Research on the process of model development for the "Condor" simulator was based on programs from Scenery Toolkit package provided by the game producer:

1) Landscape Editor - the main tool for creating new scenery, importing and exporting textures, calibrating, adding airfields, forests and local 3D objects,

\footnotetext{
${ }^{5}$ SRTM - data of terrain altitude generated basing on the measurements done by the Endeavour Space Shuttle within the Shuttle Radar Topography Mission.
} 


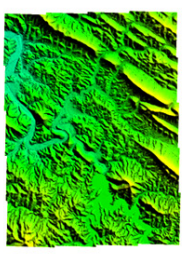

DEM

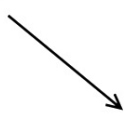

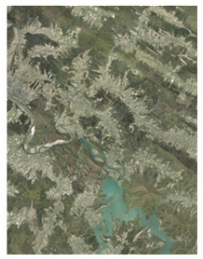

TEXTURES

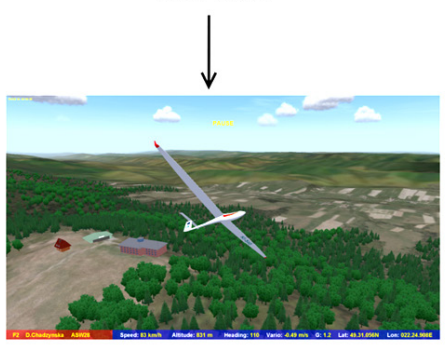

SCENERY

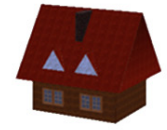

3D MODELS

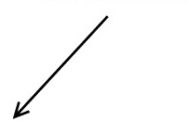

Fig. 8. Scenery components creating a model of space in the "Condor" simulator (source: D. Chądzyńska 2014)

2) RAW to TRN Converter - converter between $\mathrm{RAW}^{6}$ and $\mathrm{TRN}^{7}$ formats,

3) Object Converter - converter between $3 \mathrm{DS}^{8}$ and $\mathrm{CX}^{9}$ formats.

Additionally, the following tools proved useful or necessary during the experiments:

1) Global Mapper - advanced GIS class program used for spatial data edition,

2) 3DEM - program for visualization of terrain models,

3) Terragen - program supporting texture generation,

4) Wings3D - program for 3D graphics,

5) GIMP - graphic program used for creating textures of 3D objects.

The first criterion for selection of the above programs was their licensing method, i.e. use free of charge.

In order to create the terrain model for Condor have been used data in different formats and

\footnotetext{
${ }^{6}$ RAW format - binary file format which can hold altitude data.

7 TRN format - file format with altitude data read in the Condor program.

${ }^{8}$ 3DS - binary file format used for 3D graphic objects.

${ }^{9} \mathrm{CX}$ format - internal Condor format used for $3 \mathrm{D}$ graphic objects.
}

of different spatial range coming from three sources:

1) RTK-GPS surveying in the field performed within the project of "Geoida" Student Associotion at the Department of Geodesy and Cartography of the Warsaw University of Technology,

2) digital altitude data from the Main Geodetic and Cartographic Documentation Centre (CODGiK) in Warsaw,

\section{3) SRTM data.}

It was assumed that for the purpose of creating a terrain model for the scenery of "Bezmiechowa" (area of approx. $70 \mathrm{~km} \times 110 \mathrm{~km}$ ), data from the above sources will be integrated, and that the developed model will have a multi-resolution character (different precision in various parts of the area-most precise in the landing area and less precise further from it). Global Mapper program was used for integration. After preparing the data it was exported into SRTM format. Next, data was imported into 3DEM program. Source files contained data with coordinates in the "WGS 84" system. Simulator requires UTM coordinate system, therefore the data was transformed.

Digital orthophotomaps from CODGiK with a terrain pixel size of $0.25 \mathrm{~m}$ based on air photo- 
graphs and multispectral satellite images from LANDSAT ETM+ were used in order to achieve realistic textures. This data was then used to create a natural color composition with the help from MultiSpec. Next the model was recorded as a terrain matrix in Binary Signed Integer. The next step was to convert data into TRN format, which can be read directly by the "Condor" game (RAW to TRN Converter was used). In order to properly display the terrain model in the simulator it was necessary to calibrate it, which is performed by entering points of known geographical coordinates in Landscape Editor.
The last step of scenery preparation for the "Condor" simulator was to generate the following files: flight planner map, forest map, thermal map in Landscape Editor.

In the process of visualization the "Condor" simulator normally uses textures defined as synthetic, meaning images created in graphic programs, which represent grass, rocks, water surface, etc. However there is also an option to use photorealistic textures created on the basis of orthophotomaps and satellite images. Texture files are stored in DDS format. To obtain photorealistic textures Terragen program was

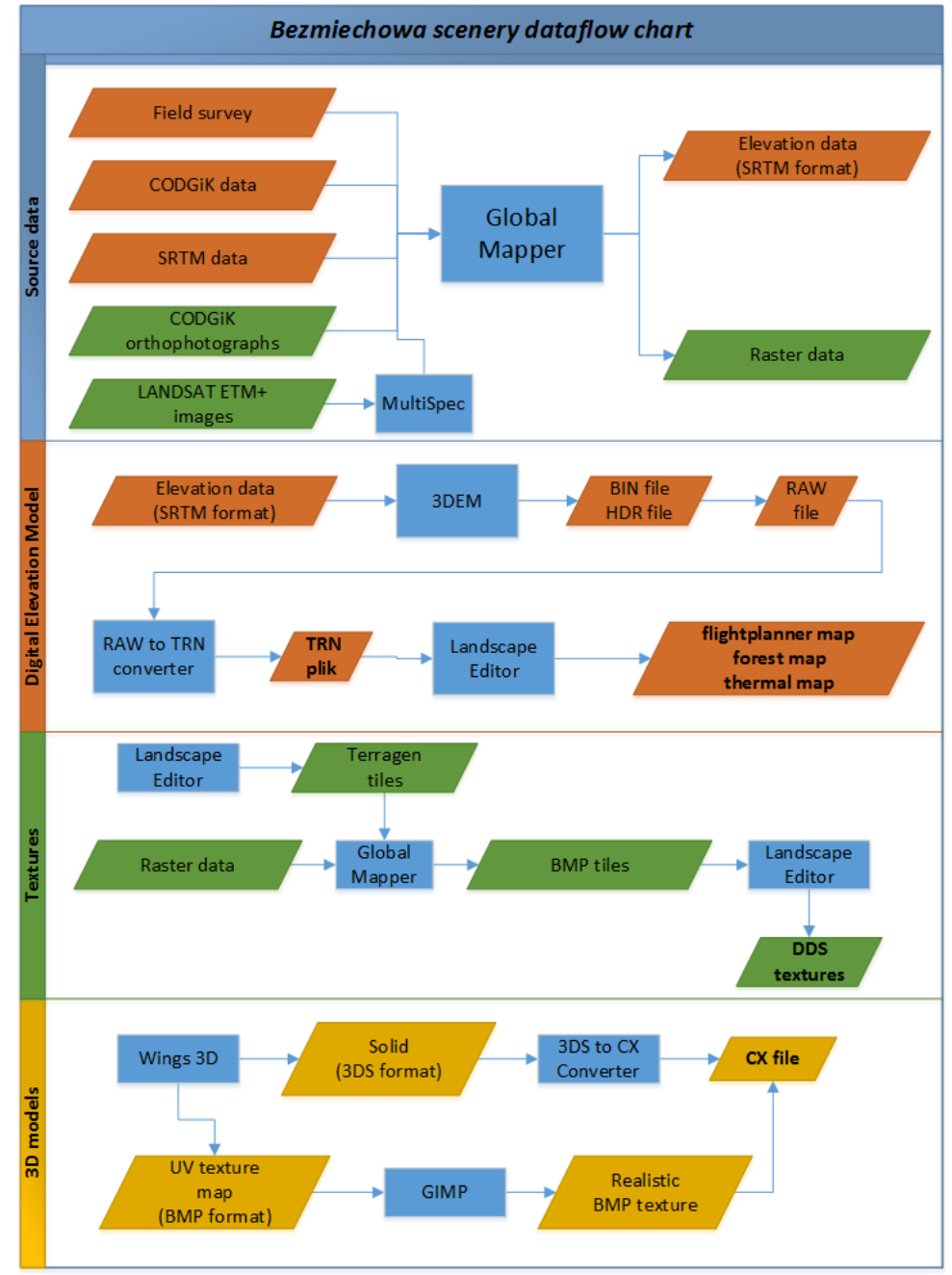

Fig. 9. Scheme of the process of Bezmiechowa scenery development (source: D. Chądzyńska 2014) 
Tab. 1. Source data used for elaboration of a terrain model of the Bezmiechowa airfield and the surrounding area

\begin{tabular}{|c|c|c|c|}
\hline & $\begin{array}{c}\text { Field } \\
\text { survey data }\end{array}$ & $\begin{array}{c}\text { CODGiK } \\
\text { data }\end{array}$ & $\begin{array}{c}\text { SRTM } \\
\text { data }\end{array}$ \\
\hline $\begin{array}{c}\text { Coordinate } \\
\text { system }\end{array}$ & 1992 & 1992 & geographic \\
\hline Format & $\begin{array}{c}\text { Maplnfo } \\
\text { TAB }\end{array}$ & ASCII & SRTM \\
\hline $\begin{array}{c}\text { File } \\
\text { extension }\end{array}$ & .tab & .ascii & .hgt, .bil \\
\hline
\end{tabular}

The table presents the used source data which made it possible to develop a terrain relief model for the purpose of the "Condor" simulator

used. It is a program used to generate virtual landscape, allowing for the creation of synthetic textures and recording them in BMP format. In Landscape Editor there is an option of exporting the terrain file into the form of so-called Terragen tiles, basing on which textures are created. The terrain file was therefore divided into even parts ("tiles") in order to achieve the necessary efficiency of the application. As a result the Condor program does not download all the data simultaneously. Synthetic textures are generated in Terragen as bitmaps (.bmp files) referring to each tile (fig. 10, fig. 11). In the case of creating photorealistic textures the source pictures collected before should be divided into parts referring to tiles as if they were bitmaps generated by the program.

The last stage of creating an advanced scenery for the "Condor" simulator is the creation of 3D models of terrain objects important for the user. "Condor" has about 80 ready 3D models of various objects which can be used in

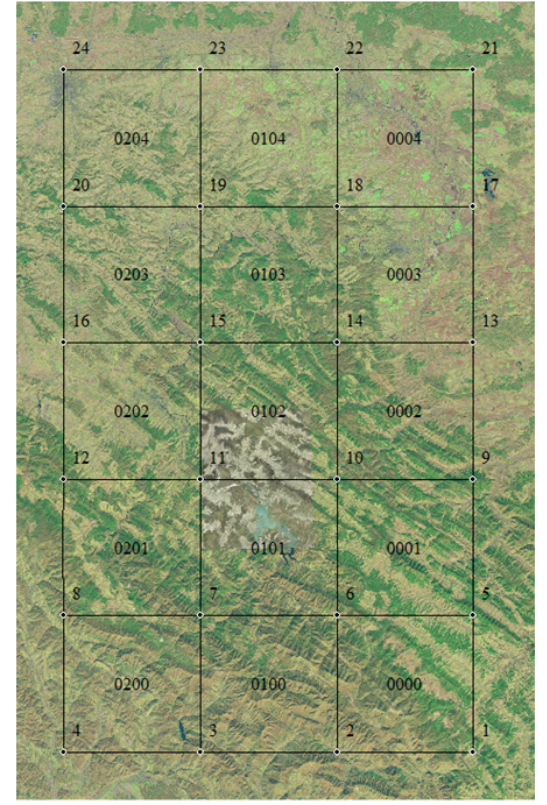

Fig. 10. Division of the terrain into "tiles" in Terragen program against the source data

the scenery (e.g. tree, building). The program also offers an option of designing own models of objects, which better represent their individual features. For the purpose of the prepared scenery three detailed models were prepared (in Wings 3D):

1) model of the main AOS building (fig. 12A),

2) model of a glider hangar (fig. 12B),

3) model of the so-called pilot house (fig. 12C).

Each of the created models consists of two components: the shape model and the superimposed texture. The objects were then exported into 3D Studio format (.3ds) which is commonly used in 3D graphics. Next the Ob-
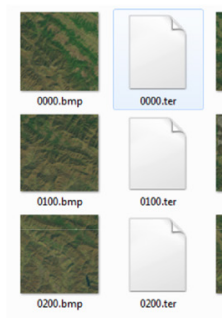
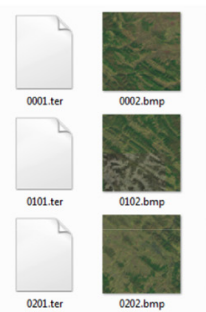
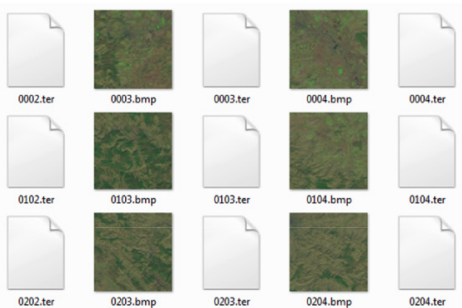

Fig. 11. Terragen folder in the Condor program with exported bitmap files (each file is a single "tile") 

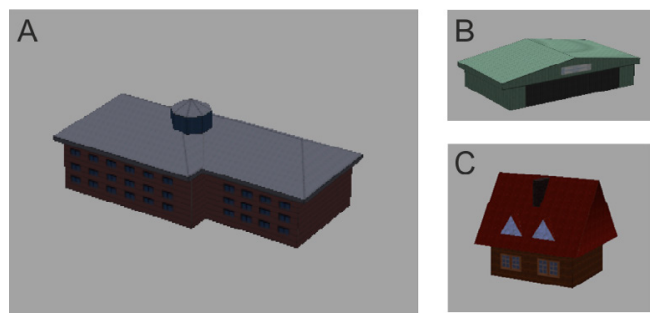

Fig. 12. Visualization of prepared 3D models: A - AOS building, $\mathrm{B}$ - glider hangar, $\mathrm{C}$ - pilot house

ject Converter tool was applied (a part of the Condor Scenery Toolkit) in order to convert the .3ds file into the internal file of 3D objects in Condor CX program. To create a texture of a 3D model one has to use the procedure marked by the producer as UV mapping. Firstly, the walls of the 3D object are drawn projected on one dimension. Next, such a 2D image is recorded as a bitmap (.bmp) which will act as texture. The file has to be further edited to make it look more realistic. Gimp graphic program was used to prepare building wall textures. The task consisted in filling the drawing of walls with textures presenting real features of object walls, e.g. writing on hangar wall, wall material (metal sheet, wood, stone), windows, etc. Next, the ready 3D models of buildings were integrated (by defining their size and location) with the scenery created earlier in the Landscape Editor program.

Apart from buildings also forests were vital for the realism of the "Bezmiechowa" scenery. It was decided that standard 3D tree models available in the Condor program will be used and multiplied in forested areas. Trees can be

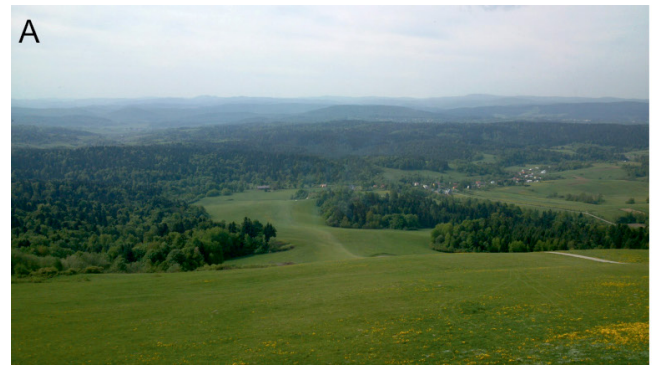

placed manually or at random. It is obviously not an accurate model of reality, but sufficient for the purpose of the game.

After applying the described procedure the scenery is ready to be used in the "Condor" simulator game. By joining the described components (terrain relief model, textures, 3D models of objects) a realistic scenery was achieved (fig. 13), which can be used for simulation of glider flights in the area of Bezmiechowa airfield.

\section{Conclusion}

Contemporary cartography is mostly a multidimensional representation of geographical space, multimedia, interactive and dynamic (P.J. Kowalski 2003). Today such models constitute an integral, key element of many video games, used for entertainment but also for education and training. Therefore, knowledge of the methods of terrain modeling using GIS technology and cartographic methodology gains importance also for game developers and users. Development of spatial data resources and spatial modeling methods will directly influence the development of video games. On the other hand, a skillful and creative use of achievements of game producers, especially a possibility to use "visualization engines" can prove valuable for the development of cartography.

Testing of the process of terrain model preparing for the "Condor" glider simulator showed that it requires some knowledge of basic methods and software in the area of GIS and computer graphics. In a relatively simple way anyone interested (even using free of charge software) can create a complex terrain model

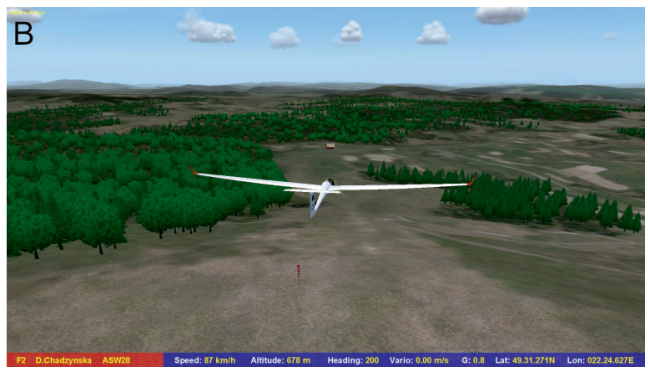

Fig. 13. Comparison of a photograph of Bezmiechowa airfield (A) with its visualization in the Condor game (B) 
and as a result obtain a realistic space visualization. The world of video games, GIS and cartography gradually interfuse, therefore the

\section{Literature}

Ahlqvist O., 2011, Converging themes in cartography and computer games. "Cartography and Geographic Information Science", Vol. 38, no. 3, pp. 278-285, DOI: $10.1559 / 15230406382278$

Blochel K., Geniviva A., Miller Z. et alli, 2012, A serious game for measuring disaster response spatial thinking. (http://www.esri.com/ /media/Files/Pdfs/ news/arcuser/0613/seriousgame.pdf).

Chądzyńska D., 2014, Możliwości wizualizacji danych geoprzestrzennych w grach komputerowych na przykładzie symulatora szybowcowego. Faculty of Geodesy and Cartography, Warsaw University of Technology, unpublished master thesis.

Despont A., 2008, Serious games et intention sérieuse:typologie. (http://www.symetrix.fr/20080215 serious-games-et-intention-serieuse-typologie/).

Gotlib D., 2011, Metodyka prezentacji kartograficznych w mobilnych systemach lokalizacyjnych i nawigacyjnych. „Prace Naukowe Politechniki Warszawskiej, seria Geodezja" Vol. 48, Warszawa: Oficyna Wydawnicza PW.

Gotlib D., Chądzyńska D., 2015, Maps in video games - range of applications, "Polish Cartographical Review", Vol. 47, 2015, no. 3, pp. 137-145, DOI: 10.1515/pcr-2015-0011

Haunert J.-H., Brenner C., Neidhart H., 2005, Using a GIS system for the generation of driving simulator Scenes (http://www.ikg.unihannover.de/fileadmin/ problematics of video games should become a subject of research of contemporary cartography.

ikg/staff/publications/Begutachtete_Zeitschriftenartikel_und_Buchkapitel/HaunertBrennerNeidhart_STISIM2005.pdf)

Kowalski P.J., 2003, Opracowanie metodyki redagowania dynamicznych prezentacji kartograficznych w systemach informacji geograficznej. Faculty of Geodesy and Cartography, Warsaw University of Technology, unpublished doctor dissertation.

\section{Internet sources}

[1] http://www.planetinaction.com/ships.htm

[2] http://www.gaiagi.com/driving-simulator/

[3] http://earth-api-samples.googlecode.com/svn/ trunk/demos/milktruck/index.html

[4] http://streetviewquiz.com/

[5] http://geoguessr.com/

[6] http://www.stisimdrive.com/

[7] http://www.microsoft.com/games/fsinsider/

[8] http://ecx.images-amazon.com/images/ I/71Ti5Q m2WIL._SL1280_.jpg

[9] http://mujweb.cz/havlikjosef/galery/MSFSX.jpg

[10] http://wiki.flightgear.org/images/thumb/5/5b/ High_textures_transitions10_1.png/300px-High_ textures_transitions10_1.png

[11] http://wiki.flightgear.org/images/5/5b/High_textures_transitions10_1.png

[12] http://www.condor-club.eu/home/1/ 